\title{
Truncus arteriosus with anterior origin of a hypoplastic main pulmonary artery
}

\author{
A S Bensky, H Velvis
}

\begin{abstract}
A newborn with an unusual form of truncus arteriosus is described, whose clinical presentation and certain features of her anatomy were more typical of pulmonary atresia with a ventricular septal defect. The morphological differentiation of certain types of truncus arteriosus and pulmonary atresia with ventricular septal defect remains an area of speculation among cardiac pathologists, and research in this area is being done using animal models. The anatomic features of the heart described in this report may assist in this discussion as the application of observations made in animal models to human cardiac development may be problematic.

(Heart 1998;79:513-515)
\end{abstract}

Department of
Pediatrics, Section of Cardiology, Bowman

Gray School of

Medicine of Wake

Forest University,

Winston-Salem,

NC 27157, USA

A S Bensky

$\mathrm{H}$ Velvis

Correspondence to: Dr Bensky.

Accepted for publication 3 November 1997

Keywords: congenital heart disease; truncus arteriosus; echocardiography

The embryological origins and morphological differentiation of certain types of truncus arteriosus and pulmonary atresia with ventricular septal defect (PA-VSD) remain controversial. We describe a patient with truncus arteriosus and previously undescribed pulmonary artery anatomy, but with a clinical presentation more typical of PA-VSD.

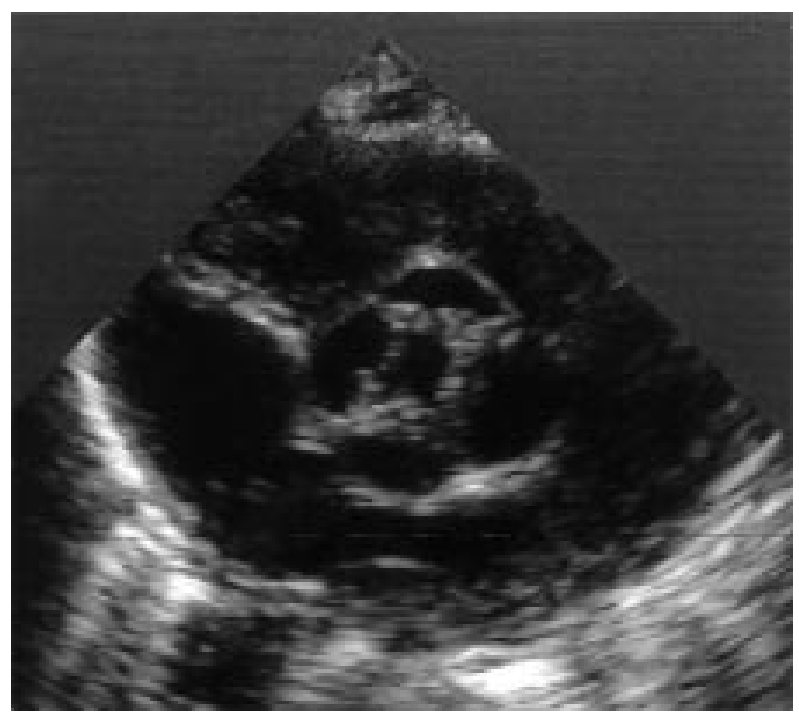

Figure 1 Short axis view of the quadricuspid truncal valve

\section{Case report}

The mother of a 30 week gestation fetus was referred for fetal echocardiography because of an abnormal obstetrical ultrasound. Echocardiography showed a common arterial trunk overriding a large ventricular septal defect, with stenosis and insufficiency of a dysplastic common arterial valve. Pulmonary arteries were not seen and a presumptive diagnosis of truncus arteriosus was made. The pregnancy continued uneventfully and arrangements were made to transfer the newborn for definitive diagnosis after birth.

At delivery, the infant was cyanotic with initial oxygen saturations of $55 \%$ in room air and an arterial $\mathrm{PO}_{2}$ of $18 \mathrm{~mm} \mathrm{Hg}$. Physical examination showed a comfortable, well developed term female infant in no distress. The cardiac examination was notable for a single S2, a grade III/VI harsh systolic ejection murmur along the left sternal border followed by a prominent diastolic murmur. Echocardiography showed visceroatrial situs solitus, normal pulmonary venous return, normal atrioventricular valves, a common arterial trunk overriding a large ventricular septal defect, and a quadricuspid truncal valve (fig 1 ) with mild stenosis and moderate insufficiency. The truncal valve appeared to have fibrous continuity with the mitral valve. There was a small

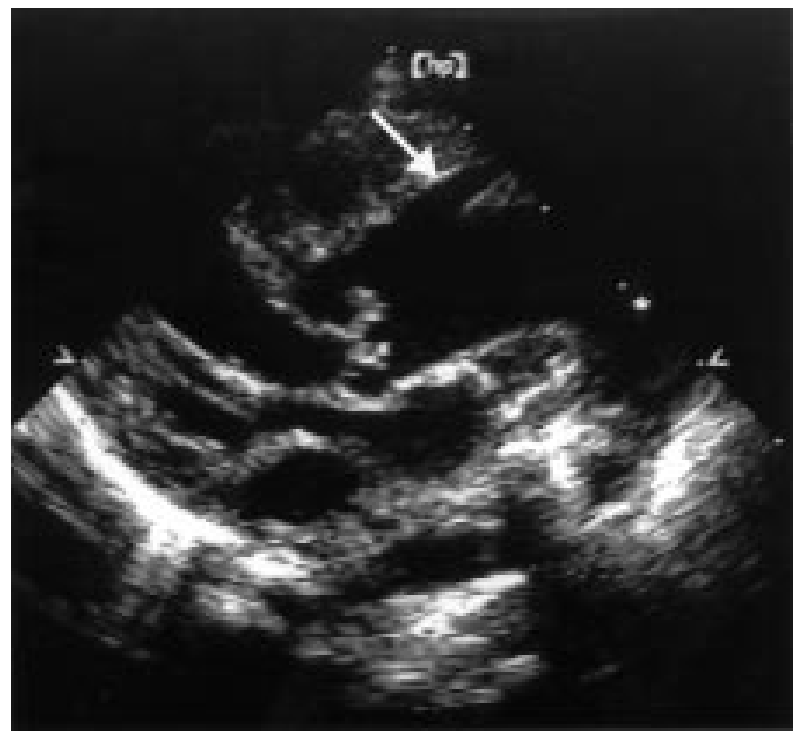

Figure 2 Parasternal long axis view showing the anterior origin of the main pulmonary artery (arrow). 


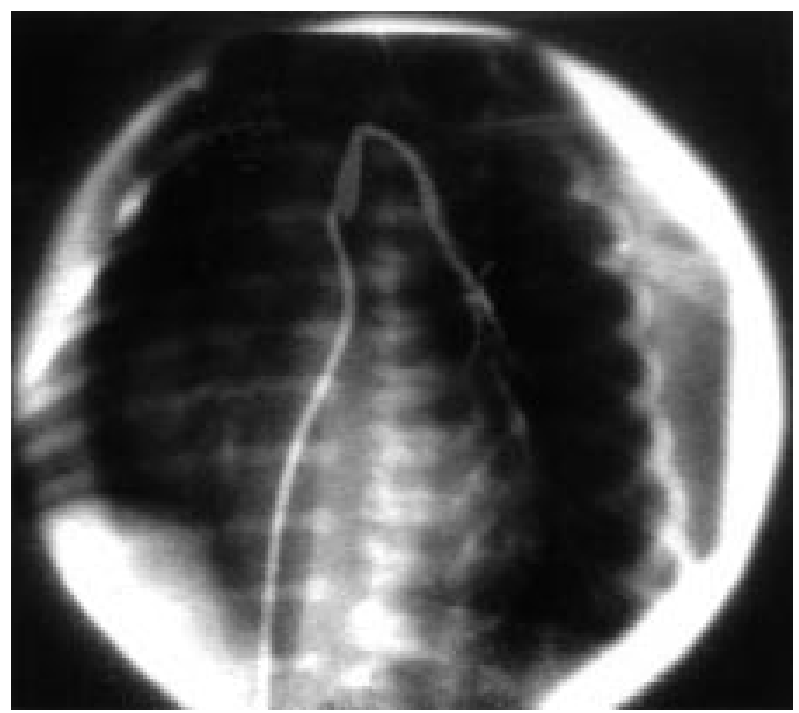

Figure 3 Selective angiogram showing the course of the main and left pulmonary artery.

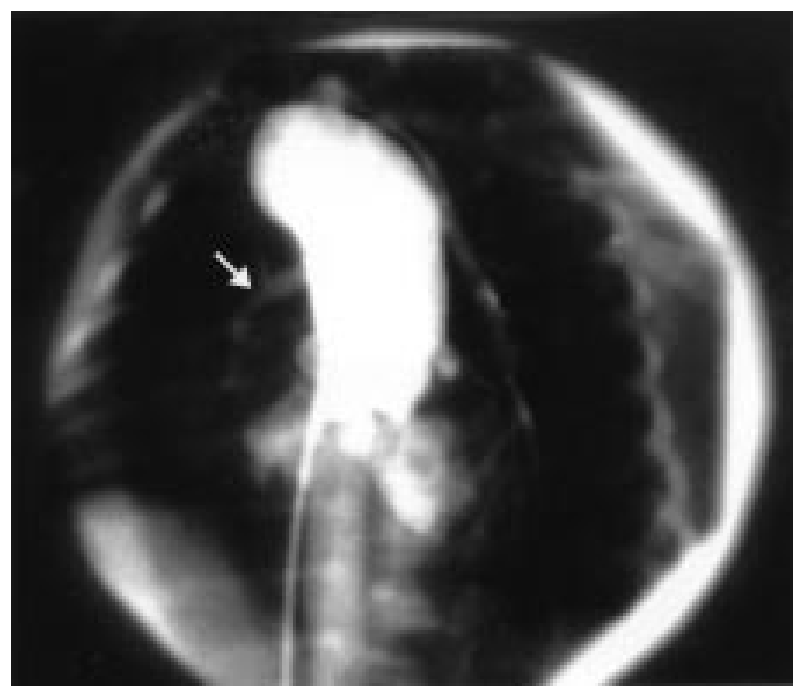

Figure 4 Truncal root angiogram showing the right aortic arch and the right pulmonary artery (arrow).
( $3 \mathrm{~mm}$ ) pulmonary artery arising from the anterior surface of the common arterial trunk $12 \mathrm{~mm}$ above the truncal valve (fig 2). This artery arched up and over the ascending aorta and continued as the left pulmonary artery. The origin of the right pulmonary artery was not well defined. The aortic arch was right sided, and there was a persistent left superior vena cava to the coronary sinus.

Other than profound hypoxaemia, no problems were encountered. Cardiac catheterisation was performed to define the sources of pulmonary blood flow and to assess the dysplastic truncal valve. This confirmed the course of the pulmonary artery as seen by echocardiography (fig 3) and showed a small right pulmonary artery arising from underneath the aortic arch (fig 4). No other significant sources of pulmonary blood flow were noted.

Because of the degree of pulmonary artery hypoplasia and the dysplasia of the truncal valve, no intervention was recommended. The infant was discharged to the care of her family, where she remained cyanotic and gained weight poorly. Her heart size increased over several months, presumably as a result of the truncal valve insufficiency. She died at six months old following a respiratory illness. The family did not consent to postmortem examination.

\section{Discussion}

There has been considerable discussion in the literature regarding the distinction between certain forms of truncus arteriosus and PA-VSD. Van Praagh's assertion that there may be a close morphological relation between the two lesions ${ }^{12}$ has been strongly contested by Anderson and Theine. ${ }^{3}$ The disagreement centres on whether truncus arteriosus results primarily from improper septation of the outflow tracts and proximal great arteries, or to a maldevelopment of the pulmonary outflow tract more akin to PA-VSD. This discussion has centred on questions such as whether the truncal valve is actually the aortic valve, and whether there is evidence for a deviated outlet septum with a blind-ending infundibulum. The presence and course of the intrapericardial pulmonary arteries are also important features. ${ }^{2}$ Recent studies of rats with teratogen induced cardiac abnormalities suggested that there may well be a common cause for the two lesions. Animals were described with truncus arteriosus who had microscopic evidence for unequal partitioning of the outflow tract, with marginalisation of the pulmonary components. Others had infundibular pulmonary atresia with pulmonary arterial supply typical of type III truncus arteriosus. The authors recognised that application of those observations to human development may be premature. ${ }^{4}$

Anatomic features found in the heart described in this report illustrate the difficulty in classifying these hearts. The common arterial valve is clearly more typical of truncus arteriosus having four well defined leaflets, functional stenosis, and insufficiency. On the other hand, neither the anterior origin of the main pulmonary artery nor the hypoplasia of the pulmonary artery branches are described in several large series of patients with truncus arteriosus. ${ }^{256}$ In PA-VSD, the blind main pulmonary artery segment can usually be traced to the base of the right ventricle anterior to the aorta, and pulmonary artery hypoplasia is frequently encountered. While anatomic dissection of the outflow tract in our patient would have allowed a more thorough discussion of the subvalvar anatomy, the features described indicate that the observations made in animal models may indeed be correct in suggesting that the two lesions are more closely related than previously thought.

The authors are grateful to Dr Stella Van Praagh for graciously 列 viding valuable insight into the lesion described.

1 Van Praagh, R. Truncus arteriosus: what is it really and how should it be classified. Eur f Cardiothorac Surg 1987;1:6570 .

2 Van Praagh R, Van Praagh S. The anatomy of common aorticopulmonary trunk (truncus arterisus comunis) and its embryological implications. Am f Cardiol 1965;16:406-26. 
3 Anderson RH, Theine G. Categorization and description of hearts with a common arterial trunk. Eur 7 Cardiothorac Surg 1989;3:481-7.

4 Jackson M, Connell MG, Smith A, et al. Common arterial trunk and pulmonary atresia: close developmental cousins? Results from a teratogen induced animal model. Cardiovasc Res 1995;30:992-1000.
5 Calder L, Van Praagh R, Van Praagh S, et al. Truncus arteiosus communis. Clinical, angiographic, and pathologic

6 Crupi G, Macartney FJ, Anderson RH. Persistent truncus arteriosus. A study of 66 autopsy cases with special reference to definition and morphogenesis. Am $\mathcal{F}$ Cardiol 1977;40:569-78.

\section{IMAGES IN CARDIOLOGY}

\section{An isolated single coronary artery}
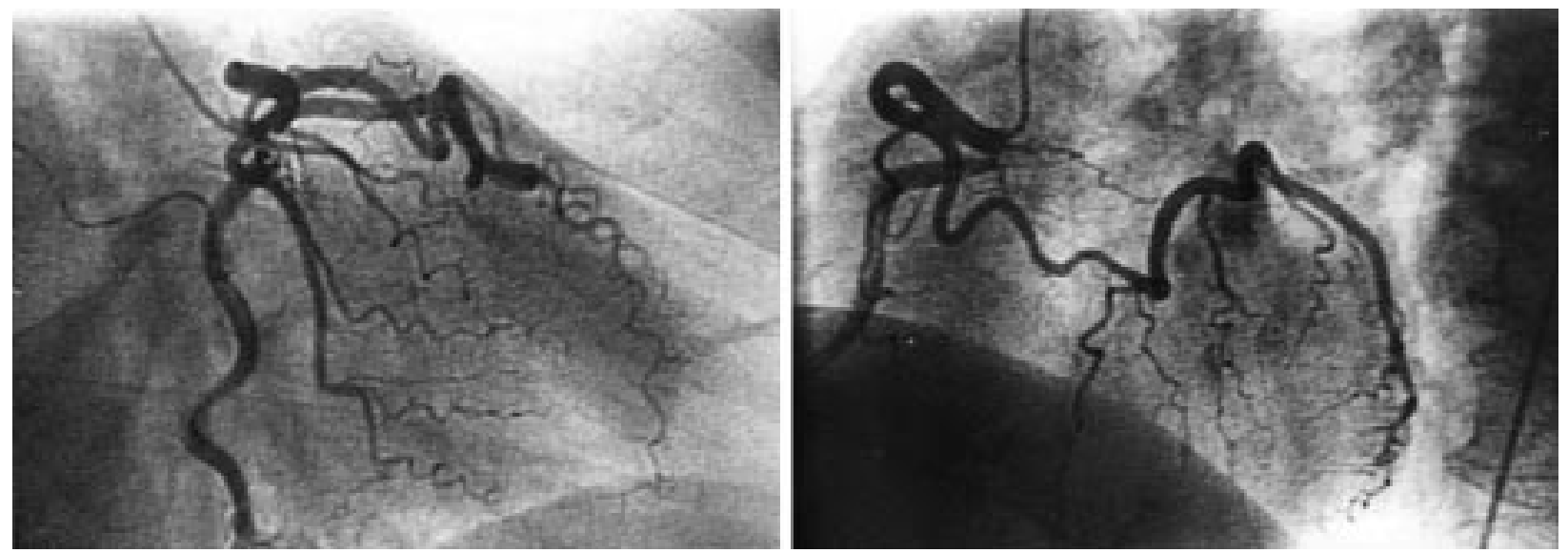

A 64 year old woman presented with chest pain. Exercise stress testing showed upsloping ST segment depression (maximally $0.15 \mathrm{mV}$ in precordial leads) without symptoms. Coronary angiography showed an isolated single coronary artery with the left main arising from the proximal part of the normal right coronary artery and crossing the base of the heart anterior to the great vessels to its inherent normal position (left, $30^{\circ}$ right anterior oblique projection; right, $60^{\circ}$ left anterior oblique projection).
Isolated single coronary artery is a very rare congenital anomaly. It occurs in approximately $0.07 \%$ of the population undergoing coronary angiography. However, in the absence of atherosclerosis the pathological importance remains speculative, despite chest discomfort combined with suspicious exercise stress testing.

S MIKETIC J CARLSSON U TEBBE 